\title{
Determine the most powerful predictor of the body image and its association with gender and body mass index in adolescent at school age in Ahvaz, South of Iran
}

\author{
Research Article
}

\section{Mojtaba Miladinia ${ }^{1}$, Nasrin Elahi' ${ }^{1}$, Pouriya Darabiyan ${ }^{2}$, Shahram Molavynejad ${ }^{1 *}$, Taiebe Kenarangi ${ }^{3}$}

\author{
1. Faculty of Nursing and Midwifery, Nursing Care Research Center in Chronic Disease, Ahvaz Jundishapur \\ University of Medical sciences, Ahvaz, Iran. \\ 2. Student Research Committee, Ahvaz Jundishapur University of Medical Sciences, Ahvaz, Iran. \\ 3. Student Research Committee, Faculty of Statistics, \\ University of Social Welfare and Rehabilitation Sciences, Tehran, Iran
}

\begin{abstract}
Introduction: The body image focuses on how to understand, think, feel, body and appearance of the body. At the age of school and adolescence, girls and boys experience different situations, so this can affect their mental image. Therefore, the aim of this study was to determine the most powerful predictor of the body image and its association with gender and body mass index in adolescent at school age in Ahvaz. Methods: This is a descriptiveanalytic epidemiologic study that examines body image in 458 high school girls and boys and its correlation with body mass index in Ahvaz city in 2018. Sampling was done by random cluster method. The data gathering tool was a demographic questionnaire, anthropometric information check list and self-body multi-dimensional relationship questionnaire to examine the mental image of the body. Data were collected using SPSS software version 17 and descriptive statistical tests and analytical at a significant level of $95 \%$. Results: The results of this study showed that the mean weight and grade point average were significantly higher in female sex. Three dimensions of mental image had a significant correlation with BMI, but overall, the mental image did not have a significant correlation with BMI. It was also the strongest predictor of the student's image, so that there was an inverse and significant relationship between the level of education and the score of mental image. Conclusion: The results indicated. there was no difference in body satisfaction in female and male subjects and BMI, and also there was a significant and inverse relationship between education level and mental image score.
\end{abstract}

Keywords: Predictor, Body image, BMI, Adolescent, Ahvaz.

\section{Introduction}

The body image focuses on how to understand, think, feel, body and appearance of the body (1) and is a multidimensional structure. The first dimension involves a cognitive or perceptual dimension related to the individual's understanding of his body that evaluates the weight, shape, and size of his body. The second dimension involves an emotional dimension that relates to emotions such as the satisfaction and concern of one's appearance. The third dimension also includes an ideal dimension that is actually related to what one wants to achieve (2). This image has been formed since birth and at the same time as the individual's development is complete and changes during the life stages of a person (3). Issues and subjects related to the mental image of the body are increasing today and affect the people of the world of all ages. This awareness begins among children from age 8 (4). Understanding the mental image of the body may be positive or negative and affected by environmental and

\section{*Corresponding Author:}

Shahram Molavynejad

Nursing Care Research Center in Chronic Diseases,

School of Nursing and Midwifery, Ahvaz Jundishapur University of Medical Sciences, Ahvaz, Iran

Email id: shahrambaraz@ajums.ac.ir social factors. Studies show that dissatisfaction with the mental image occurs during childhood and adolescence is often accompanied by an increase in negative effects (5). The factors affecting the mental image of the body include: economic status, age, gender, body mass index, weight control behaviors, individual recommendations from family members and peers about the mental image of the body and the most important factor, the media Collective $(6,7)$. Many of their normal-weight teens compare with images of very beautiful women and men presented by the media, and they suspect they are overweight and a lot of fat that thought can affect the mental image of individuals and lead to dissatisfaction that dissatisfaction can continue until puberty (8). In fact, the dissatisfaction of the mental image is the difference between the actual picture of the body and the ideal of that image in the individual's view (9).Dissatisfaction with the mental image can lead to mistaken habits in eating, wrong behaviors in weight loss, anxiety and depression $(10,8)$. In a study on high school students in Lebanon, body dissatisfaction was similar in boys and girls, while $44 \%$ of boys wanted to gain weight and $59.4 \%$ of girls wanted to lose weight (11). At the age of school and adolescence, girls and boys experience different situations, so it can affect their mental image. In this period, boys become larger and become muscular, which can be a positive experience 
than girls. However, the likelihood that boys who have lose weight or are overweight and have no muscular body has concerns about the mental image of the body. While in girls the pelvic and bone structure change, and they tend to become slimmer unlike boys (12). Of course, in a study, the results indicated that girls of normal or lower weight tend to increase their weight, whereas boys with a normal weight or more tend to lose weight (13). Of course, in the context of the body image has been much less studied in boys than in girls. The results of the studies on the effect of gender on the mental image are contradictory, and some studies indicate that there is a significant difference between the mental image of the two sexes (14-17), and others did not find a correlation between gender and body image (18-19), which this It reveals the need for further studies in this field. One of the factors that has been studied in relation to the mental image is the BMI. In a study done in Malaysia on students aged 13 to 14 years, the results indicated that $78.1 \%$ of students were dissatisfied from their mental body image, while $50 \%$ had normal BMI. Also, there was a direct correlation between BMI dissatisfaction and body image. So that the higher the BMI, the more dissatisfaction with the body image is increased (20). In another study by LATIFF et al, In 2016 on students aged 11 to 12 , the level of mental Dissatisfaction in girls was higher than of the boys, and there was a significant relationship between gender and mental image and body mass index with body image $(\mathrm{p}<0.001)(21)$.

Finally, it must be said that the body image is influenced by many factors. And in each region, the mental image differs according to the cultural, social, nutritional and racial differences. Also, the passage of time can change the mental image by changing the context of the community. Therefore, repeated research is needed at different time intervals and in different regions. Also due to the lack of a study in this field In Khuzestan and Ahvaz, and few studies in adolescent school age in Iran, researchers aimed to determine the body image in girls and boys of school age and its association with body mass index and determine its strongest predictor factor In the city of Ahvaz in order to use its results in future planning and to prevent the adverse effects of the mental image of adolescents of the school age who have the future of the country.

\section{Methods}

This is an epidemiological descriptive-analytic study that examines the body image in boys and girls in high school and its relationship with body mass index in Ahvaz city in 2018. formula

The sample size of the study was calculated using

$$
n \geq\left[\frac{\left(z_{1-\alpha / 2}+z_{1-\beta}\right)}{0.5 \times \ln [(1+r) /(1-r)]}\right]^{2}+3
$$

and similar studies (22), taking into account $r=$ 0.42 , and a significant level of 0.05 , and the power of $80 \%$, and taking into account the clustering effect $(9,10)$ 458 people were obtained. Sampling was done by random cluster method. That way four town districts were divided into 4 clusters and from among clusters randomly selected 20 clusters (high school) (10 girls' schools and 10 boy schools) and from each school, 23 students were randomly selected. The criteria for entering the study included being healthy, having informed consent, having no physical or mental illness, and willingness to participate in the study. The data gathering tool was a demographic questionnaire (age, sex, educational level, grade and area of education, etc.), anthropometric information check list (weight and height (BMI)) and self-body multi-dimensional relationship questionnaire (MBSRQ) to examine the mental image of the body. This questionnaire is used to evaluate an individual's physical image. A selfassessment scale of 46 questions, 5 options created by Cache and colleagues in 1986. The subscales of this questionnaire are:1) Appearance Evaluation, 2) Appearance Orientation, 3) Fitness Evaluation, 4) Fitness Orientation, 5) Subjective Weight, 6) Body Areas Satisfaction. The 5-choice Likert method is done (from the number 1 to the absolute option is up to 5 for the entirely acceptable option) (23). The scores of this scale are in the range of 46-231, which A higher score reflects a better and more positive image than self (24). Cash et al, Obtained a reliability of 0.89 (23). Gaeny and Parvandy obtained the correlation coefficient of this scale with the Rosenberg self-esteem scale of 0.27 (P $<0.001$ ) (44). Rahati in 2004 also evaluated the reliability and validity of this tool. And the total Cronbach alpha and subscales of $\mathrm{AE}, \mathrm{AO}, \mathrm{FO}, \mathrm{FE}, \mathrm{SW}$, BAS were $0.88,0.67,0.79,0.57,0.83,0.83,0.84$ (25). In this study, validity (content validity) and reliability (through Cronbach's alpha coefficient) were measured. After selecting the subject and obtaining consent from him and explaining the research goals and confidentiality of information and the availability of the company in the study, at first the student's demographic information was obtained through an interview by the researcher. Then, the height and weight of the individual was measured by the researcher using tape measure and digital scales, observing the correct principles (standing and with the least cover and no shoe).Subsequently, the mental image questionnaire was self-reported by the student individually and in the presence of the researcher and was asked to answer the questions carefully.

Finally, the collected data were analyzed using SPSS software version 17 and descriptive statistics (mean, standard deviation, absolute frequency, relative frequency) and analytical (T-test, Chi-square, correlation) at a significant level of $95 \%$.

\section{Results}

The findings of the study showed that the mean age of participants was $15.08 \pm 1.83$ years (male $=15.20$ \pm 1.68 ; female $=14.95 \pm 1.99$ ) and the majority of subjects were female $(54.3 \%)$. In terms of education level, $50.2 \%$ of participants was at high school and $49.8 \%$ were at guide's period. The mean BMI was higher in female participants (male $=22.44 \pm 5.24$ female $=23.22 \pm 11.90$ ). Table 1 shows demographic information and the dimensions of mental image in both sexes. According to Table 1, mean weight and mean 
grade point average were significantly higher in female sex. The overall mean of mental image was not significantly different between the two sexes.

Table 1-Comparison of Demographic Variables and Dimensions of Body Image between Two Groups

\begin{tabular}{|c|c|c|c|c|}
\hline Variables & $\begin{array}{c}\text { All participants } \\
(\mathbf{n = 4 8 4 )}\end{array}$ & $\begin{array}{c}\text { Male } \\
(\mathbf{n = 2 2 1})\end{array}$ & $\begin{array}{c}\text { Female } \\
(\mathbf{n = 2 6 3})\end{array}$ & P value \\
\hline The number of family members & $4.89 \pm 1.33$ & $4.89 \pm 1.32$ & $4.89 \pm 1.34$ & 0.984 \\
\hline Grade point average & $17.99 \pm 3.13$ & $17.53 \pm 1.67$ & $18.37 \pm 3.92$ & $0.003^{*}$ \\
\hline BMI & $22.49 \pm 4.83$ & $22.44 \pm 5.24$ & $23.22 \pm 11.90$ & 0.366 \\
\hline Total of dimensions of body image & $174.73 \pm 18.21$ & $173.96 \pm 19.04$ & $175.37 \pm 17.49$ & 0.399 \\
\hline
\end{tabular}

Table 2 shows the correlation between mental image and body mass index. Three dimensions of mental image had a significant correlation with BMI, but overall, the mental image did not have a significant correlation with BMI.

Table 2- correlation between body image dimensions with Body Mass Index (BMI)

\begin{tabular}{|l|c|}
\hline \multicolumn{1}{|c|}{ Body image dimensions } & $\begin{array}{c}\text { BMI } \\
\text { (Pearson correlation) }\end{array}$ \\
\hline Appearance Evaluation: AE & 0.027 \\
\hline Appearance Orientation: AO & 0.045 \\
\hline Fitness Evaluation: FE & $-0.104^{*}$ \\
\hline Fitness Orientation: FO & $-0.123^{* *}$ \\
\hline Subjective Weight: SW & $0.315^{* *}$ \\
\hline Body Areas Satisfaction: BAS & -0.050 \\
\hline Total of dimensions of body image & -0.042 \\
\hline
\end{tabular}

Data are presented as Pearson correlation.

** Correlation is significant at $\mathbf{0 . 0 1}$ level.

* Correlation is significant at 0.05 level.

Table 3 shows the predictive power of the mental image in each variable. In this study, the strongest predictor of mental image is the educational level, so there was a significant and inverse relationship between the level of education and the score of mental image.

Table 3- predictor of body image, with $95 \%$ confidence interval

\begin{tabular}{|l|l|l|}
\hline Variables & Standardized coefficient (Beta) & P value \\
\hline Age & -0.081 & 0.07 \\
\hline Gender & 0.038 & 0.399 \\
\hline Education level & -0.132 & $0.004^{*}$ \\
\hline the number of family members & 0.037 & 0.416 \\
\hline What number child are you in your family? & -0.002 & 0.968 \\
\hline grade point average & 0.018 & 0.694 \\
\hline Weight & -0.035 & 0.437 \\
\hline Height & 0.032 & 0.485 \\
\hline BMI & -0.042 & 0.361 \\
\hline
\end{tabular}

Data are presented as Standardized coefficient (Beta) and $P$ value.

Liner regression was used.

* Significant difference (P value<.05).

\section{Discussion}

The present study was conducted to evaluate the relationship between the body image with sex and body mass index, in girls and boys of school age, in Ahvaz city. Based on the findings of the study, the results showed among the studied data, $54.3 \%$ of them were female and the average age was $15.88 \pm 1.83 \%$. Weight Average and grade point average in female was more than male.

So that weight Average and grade point average in female were 57.80 \pm 12.58 and $18.37 \pm 3.92$ respectively and in males it was equal to $67.33 \pm 42.05$ and $17.53 \pm 1.67$. The results of previous studies provide different information.

In this regard, in the study of Darabiyan et al, to determine the prevalence of obesity in middle-level students The ages of 12-16 years old in Ahvaz were conducted in 2018, Showed that 18.8\% (45 people) of Ahvaz students had obesity and $22.2 \%$ (53 people) were overweight. In boys, the prevalence of obesity and overweight was $25.6 \%$ (31) and $17.4 \%$ (21 people) and in female students, obesity and overweight were $11.9 \%$ (14 people) and $27.1 \%$ (32). Also, there was a significant difference between height and weight in both male and female sexes, but 
BMI was similar in two groups So that boy students had overweight and obesity more than girls, which did not match the results of the present study (26). Also, in Haidari's study, the mean of anthropometric indices (weight, height, BMI) in male students was higher than that of female students. In boys, obesity was $2.4 \%$ and overweight was $16.1 \%$ and in girls, obesity was $3.9 \%$ and overweight was $12.2 \%$, and the difference was not significant between boys and girls (30). The results of the study by Sophia et al, Conducted in 2015 on high school students in New York City Over the years 20062011, showed that the prevalence of obesity and overweight in male students was higher (35). In the studies of AL-Hazzaa et al, Which was conducted on 2908 Saudi students, the prevalence of obesity in boys was $24.1 \%$ and in girls was $14 \%$. The results of these studies were not consistent with our current study. Different reasons for the prevalence of obesity in males and females in Iran and other countries include lifestyle, diet, physical activity in different areas, and the application of different methods in sampling. In this study, there was no significant difference between the general mean mental images of the two gender.

In a study by jacklin et al, Conducted in 2015 with the aim of examining body perception and satisfaction in overweight children in a weight management program, they found that there is no relationship between gender and mental image, or the difference in body satisfaction with Age or gender was not observed (18).

Also, in the study of Kargar et al., Which was conducted in 2014 with the aim of examining the relationship between body image and body mass index, consumption of pollen and physical activity in staff members of the University of Science, they found that there was a weak correlation between body mass index And undesirable body image. However, body mass index and body image have no significant difference in both gender (19). In the present study, there is no significant difference in the amount of undesirable body image between male and female students. This is similar to another study that was conducted on female and male students in the United States. In the final model, there was no significant difference between the two genders in terms of body image (27). The results cited were consistent with the study. But studies that are inconsistent with the present study, which show the difference in body image of the body in both genders, include more research and articles. In the research shown, there is a difference in the body's desirable size between men and women, and women prefer a smaller body size (28). The report of the Ministry of Health, Medical Education and Research on Adolescents has also revealed a clear difference in body image in both sexes (29).Another research that was conducted in Tehran also showed that the Girls consider themselves obese and Boys consider themselves thinner (30). Another study in Italy showed that girls are more likely to lose weight than boys, and their dissatisfaction with their body image is higher (31). The higher average age of the research can be one of the reasons for the lack of gender differences. The other results of this study showed that three dimensions of mental image such as Fitness Evaluation, Fitness Orientation and Subjective Weight have a significant correlation with BMI, but in general, there is no significant correlation between mental image and BMI. In a study done in Malaysia on 13-14 year-old students, the results indicated that whatever the BMI, to be more, Dissatisfaction with the mental image becomes greater. Which is not consistent with the current study. The results of Thomas et al, In the United States of America, showed that the research units had a high degree of satisfaction with physical mental imagery in all four areas of Appearance Evaluation, Body Areas Satisfaction, Subjective Weight and Appearance Orientation (32). The results of the research, Kornblau et al., in the south of the state of Texas'Indicating the satisfaction of the units under study from the physical mental image. That did not coincide with our study. Dehghani et al. Also showed a significant difference between BMI and different areas of body image satisfaction, so that students with natural and lean BMI, felt the physical attractiveness and higher satisfaction with the appearance and satisfaction of different body parts they had. And students with low BMI got the slightest worry and anxiety about weight, obesity, and diet. which did not match the results of our study (33). However, Kerr et al, did not show any significant correlation with BMI in the field of appearance evaluation, which was consistent with our study. In the present study, the predictor variables such as age, sex, level of education, number of family members. The variable of the educational level is the strongest predictor. There is a reverse and significant relationship between educational level and mental image score.

In this way, in a study by Lamian et al. In 2013, aimed at examining the relationship between Literacy, The quality of life and the mental image of women was carried out, Found that in examining the relationship between the level of health literacy and mental image, the highest frequency in the level of mental image is disrupted $(8.8 \%)$ of people who have high and adequate levels of literacy. And with the increase in education, the mental image of women makes up more of a disorder that is consistent with the present study (34). Findings of chehrazi et al, Showed that, whatever the higher the level of education, the score for their mental image is lower. Teenage girls of guidance school Have a better mental body image than high school girls, which is consistent with our study (35). Another study showed that the average satisfaction of physical body image in the areas of evaluation of the appearance and satisfaction of different parts of the body in both genders at adolescence was high, which shows the physical attractiveness and high satisfaction of the samples studied from the apparent state and satisfaction of different parts of the body. Which did not coincide with the present study, which considered the level of education as the strongest predictor variable (36). Other research results show that inappropriate mental image was seen in $46 \%$ of women and only in $34 \%$ of men, which did not show significant statistical differences. The average age of these individuals was higher (33 
years) as for the research done by younger people, it can be one of the reasons for the lack of gender differences.

Increasing the age, increasing the number of family members and conflicts in the education of children is one of the things that reduce the mental image of women. Therefore, there was no significant difference between men and women participating in the study. The results of this study were not consistent with the present study. Also Studies in other parts of the world, such as Brazil, the United States, Latin America, have been shown to reverse the relationship between age and mental image, and have linked age, weight gain, and body fat mass with an inappropriate mental image. It is therefore advisable to have a better mental image in people of high age, with weight loss and body fat mass. Based on the findings of this study, the educational level is the strongest predictor variable among other variables such as age, sex, number of family members, and so on. And whatever the higher the level of education, the lower the body image score.

Therefore, it is recommended that by adding sports facilities and increasing physical activity in educational settings and implementing appropriate training programs, a step towards improving the mental image of students is taken. Which itself sleads to increased efficiency during the course of study.

\section{Conclusion}

The results of this study indicated that there was no significant difference between body image of the subjects with BMI and sex, in other words, there was no difference in body satisfaction in female and male subjects and BMI. There was also a significant and inverse relation between education level and mental image score. Finally, it must be said that the mental image is influenced by many factors. And in each region, the mental image differs according to the cultural, social, nutritional and racial differences. Also, the passage of time can change the mental image of individuals. The results of this study can be used to prevent undesirable body image in adolescents of the school age, who have the future of the country in their hands. Due to the lack of access to all students, it is recommended to conduct studies with a larger sample size and to measure dietary factors and mental health at primary level until the end of high school.

\section{Acknowledgments}

This article is from a research project With SDH9508 code approved by Ahvaz Jundishapur University of Medical Sciences, sponsored by the research assistant. In this way, the authors thank and appreciate from the directors of the schools under study, who have been cooperating sincerely.

\section{References}

1. National Eating Disorders Collaboration. What is body image?.Available at:http://www.nedc.com.au/ body-image.[Accessed 12 June 2017].

2. As-Sa'edi E, Sheerah E, Al-Ayoubi R, Al-Jehani A, Tajaddin W, Habeeb H. Body image dissatisfaction: Prevalence and relation to body mass index among female medical students in Taibah University, 2011. Journal of Taibah University Medical Sciences 2013; 8(2): 126-133.

3. Amidi M, Ghofranipour F, Hoseini R. Relationship between body image dissatisfaction and body mass index in the adolescence girls. Behavioral science research 2006; 4(1): 59-65. [Persian]

4. Heron KE, Smyth JM, Akano E, Wonderlich SA. Assessing body image in young children: a preliminary study of racial and developmental differences. SAGE Open 2013; 3(1). 2158244013478013.

5. Ferreiro F, Seoane G, Senra C. Toward understanding the role of body dissatisfaction in the gender differences in depressive symptoms and disordered eating: a longitudinal study during adolescence. J Adolesc 2014; 37(1): 73e84.

6. Pon Jr LW, Kandiah M, Mohd Nasir MT. Body image perception, dietary practices and physical activity of overweight and normal weight Malaysian female adolescents. Malays JNutr 2004; 10(2): $131 \mathrm{e} 147$.

7. Dehghani M, Chehrzad M, Jafari Asl M, Soleimani R.Evaluate the relationship between body image satisfaction with the socio-cultural patterns Teenage girls in Rasht. Journal of Hamadan Nursing and Midwifery, 2013; 20(3): 26-34. [Farsi]

8. Chang F-C, Lee C-M, Chen P-H, Chiu C-H, Pan YC, Huang T-F. Association of thin-ideal media exposure, body dissatisfaction and disordered eating behaviors among adolescents in Taiwan. Eat Behav 2013; 14(3): 382e385.

9. Costa, Larissa da Cunha Feio, et al. "Association between body image dissatisfaction and obesity among schoolchildren aged 7-10 years." Physiology \& behavior 160 (2016): 6-11

10. Forse'n Mantilla E, Bergsten K, Birgega ${ }^{\circ}$ rd A. Self -image and eating disorder symptoms in normal and clinical adolescents.Eat Behav 2014; 15(1): $125 \mathrm{e} 131$.

11. SUKARIYAH, Mohamad B.; SIDANI, Rihab A. Prevalence of and gender differences in weight, body, and eating related perceptions among Lebanese high school students: Implications for school counseling. Procedia-Social and Behavioral Sciences, 2014, 159: 184-191.

12. Huebscher B. Relationship Between Body Image and Self Esteem Among Adolescent Girl [dissertation]. The Graduate School, University of Wisconsin -Stout; 2010

13. Xie B, Chou CP, Spruijt-Metz D, Reynolds K, Clark F, Palmer PH, et al. Weight perception and weightrelated sociocultural and behavioral factors in Chinese adolescents.Prev Med. 2006;42(3):229-234.

14. Pahlevanzadeh S, Maghsoudi H, Ghazavi Z, Habibpour z. relationship between body image and body mass index in the adolescences. Journal of behavioral sciences research center 2005; 3(1).

15. Sanagoo A, Jouybari L M, Ghanbari Gorji M. Study of Body Image of Staff Engaged in Golestan University of Medical Sciences. Journal of Boye Gorgan nursing and midwifery school 2011; 8(2): 
77-85. [Persian]

16. Jung J, Peterson M. Body dissatisfaction and patterns of media use among pre-adolescent children. Family and Consumer Sciences Research Journal 2007; 36(1): 40-54.

17. Khan A N, Khalid S, Khan H I, Jabeen M. Impact of today's media on university student's body image in Pakistan: a conservative, developing country's perspective. BMC Public Health 2011; 11: 379- 87 .

18. O’Connor J N, Golley R K, Perry R A, Magarey A M, Truby $\mathrm{H}$. A longitudinal investigation of overweight children's body perception and satisfaction during a weight management program. Appetite 2015; 85: 48-51.

19. Kargarnovin Z, Asadi Z, Rashidkhani B, Azar M. Assesing Body Image and Its Relation with Body Mass Index, Food Group Consumption and Physical Activity Among the University of Economic Sciences. Iranian Journal of Endocrinology and Metabolism 2013; 14(5): 455-509. [PERSIAN]

20. Farah Wahida Z, Mohd Nasir MT, Hazizi AS. Physical activity, eating behaviour and body image perception among young adolescents in Kuantan, Pahang, Malaysia. Malays J Nutr 2011; 17(3): $325 \mathrm{e} 336$.

21. LATIFF, Azmira Ab; MUHAMAD, Juliawati; RAHMAN, Razlina A. Body image dissatisfaction and its determinants among young primary-school adolescents. Journal of Taibah University Medical Sciences, 2018, 13.1: 34-41.

22. Vander Wal J.S, Thelen M.H. Predictors of body image dissatisfaction in elementary-age school girls. Eating Behaviors 2000; 1: 105-122

23. Cash, j. The body image work book: An 8 step program for learning to live your looks" New Harbinger: OQKland. 1997.

24. Gaeny, A. Parvandy, M. Parvandy, Z. The relationship between body image and selfesteem in women, Thesis of Master degree, University of Mohaghegh Ardabil 2008. (persian)

25. Rahati A. Evolutionary Study of body image and its relationship with self-esteem based on comparison between adolescent, middle age and old people. (Dissertation), Tehran: Shahed University 2004. (Text in Persian).

26. Darabiyan, P., Baraz, S., Elahi, N., Miladinia, M., Saberipour, B., Alasvand, M., \& Jabangirimehr, A. (2018). AN INVESTIGATION OF PREVALENCE OF OBESITY AND ITS RELATED DEMOGRAPHIC FACTORS IN STUDENTS
AGED 12-16 YEARS OLD IN AHVAZ IN 2017. Indo American Journal of Pharmaceutical Sciences, 5(1), 413-419.

27. Safavi M, Mahmoodi M, Roshandel A. The relation of body image and eating disorders in female students of Tehran Central Azad University. Medical Science Journal of Islamic Azad University 2015; 19: 129-34. [Farsi]

28. Saules KK, Collings AS, Hoodin F, Angelella NE, Alschuler K, Ivezaj V, et al. The contributions of weight problem perception, BMI, gender, mood, and smoking status to binge eating among college students. Eat Behav ;2014 10: 1-9.

29. Mohammadpour-Ahranjani B, Rashidi A, Karandish M, Eshraghian MR, Kalantari N. Prevalence of overweight and obesity in adolescent Tehrani students,2015: an epidemic health problem. Public Health Nutr 2004; 7:

30. Omidvar N, Eghtesadi Sh, Ghazi-Tabatabayee M, MinayeeS, Samareh S. Assesing body image and its relation with body mass index, food consumption patterns amongadolescent in Tehran. Journal of the Faculty ofMedicine 2014; 26: 257-64. [Farsi]

31. Bulik CM, Wade TD, Heath AC, Martin NG, StunkardAJ, Eaves LJ. Relating body mass index to figural stimuli: population-based normative data for Caucasians. IntJ Obes Relat Metab Disord 2013 25: 1517-24.

32. Thomas LA. Body image concerns in africanamerican adolescent females as influenced by acculturation. dissertation for the degree of doctor of psychology, University of Hartford 2014

33. M. Dehghani, M.Sc., M.M. Chehrzad, M.Sc., M. Jafari Asl, M.Sc.. Investigating the Relationship between Satisfaction from Body Image and Socio Cultural Patterns among Female Adolescents in Rasht City. Avicenna J Nurs Midwifery care. 2012; 20 (3) :26-36

34. Maryam dehghani i E, et al. Study on factors of body image in Japanese and Vietnamese adolescents. J Nutr Sci Vitaminol 2013

35. Mino chehrazi Prevalence of obesity and over weight in adolescents and adult population in shiraz. Iran JEndocrinolMetab 2014; 7: 51-66. (Persian).

36. Momeni M, Ghorbani A, Hasandoost F. Predictors of Body image dissatisfaction among students of Qazvin University of Medical Sciences. IJPN. 2016; 4 (1) :28-37. 